\title{
Epidemiology of inflammatory bowel disease among an indigent multi-ethnic population in the United States
}

This article was published in the following Dove Press journal:

Clinical and Experimental Gastroenterology

6 December 2010

Number of times this article has been viewed

\section{Hoda M Malaty ${ }^{1,2}$ \\ Jason K Hou ${ }^{1,2}$ \\ Selvi Thirumurthi'}

'Department of Medicine, Baylor College of Medicine, Veterans Affairs Medical Center, Houston, Texas , USA; ${ }^{2}$ Michael E DeBakey Veterans Affairs Medical Center, Houston, Texas, USA
Correspondence: Hoda M Malaty 2002 Holcombe Blvd, VA Medical Center (IIID), Houston, Texas 77030, USA

Tel + I 7137947280

Fax +I 7I3790 I040

Email hmalaty@bcm.tmc.edu
Background: Environmental factors, including socioeconomic status, may affect inflammatory bowel disease (IBD). There is a paucity of data on the epidemiology of IBD among patients of low socioeconomic status.

Aim: To examine the epidemiologic features of IBD among African-American, Hispanic, and Caucasian patients from a county hospital, where the majority of the patients are socioeconomically disadvantaged.

Methods: A retrospective study was conducted on a cohort of patients diagnosed with IBD based on clinical, radiologic, endoscopic, and histological data. We reviewed charts of adults aged 20-70 years diagnosed with IBD between 2000 and 2006. Demographic data, disease subtype, and phenotypic features of IBD were recorded based on the Montreal Classification. The data were analyzed using the chi-square, Fisher exact, Wilcoxon rank-sum, and Student's $t$-tests.

Results: The study cohort included 273 patients, with 54\% female, 30\% Caucasian, 44\% African-American, and 26\% Hispanic. Over half (54\%) of the patients had Crohn's disease (CD), and $46 \%$ had ulcerative colitis (UC). The mean age at diagnosis was $40 \pm 14$ years with no significant difference between CD and UC (age $43 \pm 13$ versus $44.5 \pm 14$, respectively; $P=0.5$ ). Females were diagnosed at a significantly later age than males ( $46 \pm 13$ years versus $40 \pm 13$, respectively; $P=0.001$ ). This trend remained significant for females with CD and UC, and across each racial/ethnic group. Hispanic patients were diagnosed with UC more often than Caucasian patients (64\% versus 34\%; odds ratio [OR] 3.5; 95\% confidence interval [CI]: $1.8-6.5$, $P=0.0003$ ) or African-Americans (64\% versus 43\%; OR 2.3; 95\% CI: $1.3-4.3, P=0.005$ ). Among the 147 patients with $\mathrm{CD}, 54 \%$ had fistulizing and/or stricturing disease. The prevalence of fistulizing, stricturing, and inflammatory $\mathrm{CD}$ was similar across all age, gender, and racial/ ethnic groups.

Conclusions: Within an indigent population, UC was diagnosed more often in Hispanics than CD. Females were diagnosed at a significantly older age than males across all racial/ethnic groups. There was no difference in the CD phenotypes between the three ethnic groups. Understanding the epidemiology of IBD will require examination of the interactions between gender, race/ethnicity, and environmental factors.

Keywords: IBD, ethnicity, indigent, epidemiology

\section{Introduction}

The term inflammatory bowel disease (IBD) includes Crohn's disease (CD) and ulcerative colitis (UC) and is ranked among the five most prevalent gastrointestinal diseases in the United States. ${ }^{1}$ IBD is estimated to affect over one million patients in the United States and be responsible for annual health care costs exceeding US\$1.7 billion. ${ }^{1-4}$ The etiology and the natural history of IBD are both influenced 
by environmental and genetic factors. IBD is considered a complex polygenic disorder in which the genotypic profile influences the disease characteristics. ${ }^{5-6}$ Environmental exposures such as cultural background, socioeconomic status, and diet are also important, although data concerning environmental-genetic interactions are sparse. ${ }^{5}$

Our current understanding of the epidemiology, prognosis, and treatment of IBD is currently based primarily on studies conducted in Caucasian populations, ${ }^{7-9}$ despite the fact that over the last two decades the incidence of hospitalizations for IBD among African-Americans has begun to approach that of Caucasians. ${ }^{10-12}$ Our aim was to examine the epidemiologic features of IBD among multiethnic patients in a county hospital that primarily serves patients of low socioeconomic status. We also evaluated these patients for differences in IBD phenotype between racial/ethnic groups.

\section{Materials and methods Study design}

We performed a cross-sectional study of all patients with IBD treated in the Harris County Hospital District (HCHD) between 2000 and 2006. Patients with IBD were identified using diagnostic codes from the International Classification of Disease (ICD) 9th (555.x [CD] and 556.x [UC]) and 10th editions (K50.x [CD] and K51.x [UC]). Primary medical record review was performed by a gastroenterologist (JKH) using a standardized abstraction form.

The diagnosis of IBD was confirmed based on findings consistent with current practice criteria. Patients with a history of bowel resection prior to seeking care within the HCHD were eligible for inclusion without histologic confirmation. Perianal surgery included fistulotomy, abscess drainage, or seton placement. Patients with a non-IBD diagnosis on follow-up (infection, ischemia, or malignancy) or indeterminate colitis were excluded, as were patients under the age of 18 years.

\section{Study setting}

HCHD comprises three inpatient facilities and 13 outpatient clinics and serves the residents of the third most populous county in the United States. Over 40,000 hospital admissions and more than 900,000 clinic visits occurred in the HCHD between 2000 and 2006. ${ }^{14}$ Sixty percent of the patients are charity/self-pay and nearly $60 \%$ are Hispanic. More than half of the patients in the HCHD are female (HCHD internal data source). This study was conducted with the approval of the Baylor College of Medicine and HCHD Institutional Review Boards.

\section{Data collection}

The HCHD uses the EpicWeb (Epic Systems Incorporated, Wisconsin, MN, USA) electronic medical record (EMR) system. This EMR contains laboratory, endoscopy, radiology, and pathology reports; limited inpatient records (admission history and physical and discharge summaries); and ambulatory care records.

Demographic data including age, gender, and race/ ethnicity were recorded for each study patient. Race/ethnicity was based on patient self-report in the medical record. Only data involving African-American, Caucasian, and Hispanic patients were included in this study due to the small sample size of the other ethnic groups.

IBD characteristics were recorded for each study patient. $\mathrm{CD}$ and UC location and phenotype were classified according to the Montreal Classification. The extent of UC was determined based on evidence of endoscopic or histological activity. The phenotype of CD was identified as fistulizing, stricturing, or inflammatory disease based on available data.

\section{Statistical analysis}

Categorical variables were compared using chi-square and ANOVA tests. Continuous variables were compared using Wilcoxon rank-sum and Student's $t$-tests. Age was analyzed as a continuous variable and was also categorized into five groups by each decade. Statistical analysis was performed using SAS version 4.0 Software. ${ }^{13}$

\section{Results}

The study cohort included 273 patients with $54 \%$ female, $30 \%$ Caucasian, 44\% African-American, and 26\% Hispanic. Over half of the patients had CD and $46 \%$ had UC (Table 1 ). The mean age at diagnosis was $40 \pm 14$ years with no significant difference between CD and UC (age $43 \pm 13$ versus $44.5 \pm 14$, respectively; $P=0.5$ ). Female patients with IBD were diagnosed at a significantly later age than male patients, and this trend was consistent for both CD and UC. Although this trend was seen among all three racial/ethnic groups, it was significant among the African-American patients. Hispanic patients were diagnosed with UC more often than Caucasian $(64 \%$ versus 34\%; odds ratio [OR] 3.5; 95\% confidence interval [CI]: $1.8-6.5, P=0.0003)$ or African-American patients $(64 \%$ versus $43 \%$; OR 2.3 ; 95\% CI: $1.3-4.3, P=0.005$ ). Caucasians were diagnosed with CD more often than UC (Figure 1).

\section{Crohn's disease characteristics}

The prevalence of the inflammatory phenotype was significantly greater than stricturing disease $(65 \%$ versus 
Table I The mean age of diagnosis/presentation of inflammatory bowel disease by gender among the 273 adults in the study

\begin{tabular}{|c|c|c|c|c|c|c|c|c|c|c|c|c|}
\hline & \multicolumn{4}{|c|}{ All patients $(N=273)$} & \multicolumn{4}{|c|}{ Crohn's disease $(N=147)$} & \multicolumn{4}{|c|}{ Ulcerative colitis $(N=126)$} \\
\hline & $\begin{array}{l}\text { Total } \\
\text { number }\end{array}$ & $\begin{array}{l}\text { Mean } \\
\text { age }\end{array}$ & $\pm \mathbf{S D}$ & $P$ & $\begin{array}{l}\text { Total } \\
\text { number }\end{array}$ & $\begin{array}{l}\text { Mean } \\
\text { age }\end{array}$ & \pm SD & $P$ & $\begin{array}{l}\text { Total } \\
\text { number }\end{array}$ & $\begin{array}{l}\text { Mean } \\
\text { age }\end{array}$ & $\pm \mathbf{S D}$ & $P$ \\
\hline \multicolumn{13}{|c|}{ Total population } \\
\hline Males & 125 & 40.1 & 13.9 & $0.02 *$ & 63 & 38.2 & 15.1 & $0.001 *$ & 62 & 41.5 & 13.5 & $0.03 *$ \\
\hline Females & 148 & 46.4 & 13.9 & & 84 & 46.0 & 13.0 & & 64 & 47.0 & 15.3 & \\
\hline \multicolumn{13}{|c|}{ African-Americans } \\
\hline Males & 48 & 39.2 & I4.I & $0.001 *$ & 30 & 38.8 & 13.9 & $0.03 *$ & 18 & 40.5 & 14.1 & $0.02 *$ \\
\hline Females & 72 & 48.1 & 13.8 & & 38 & 46.1 & 13.1 & & 34 & 50.4 & 14.0 & \\
\hline \multicolumn{13}{|c|}{ Caucasians } \\
\hline Males & 37 & 41.2 & 13.5 & 0.65 & 18 & 36.8 & 13.6 & $0.05^{*}$ & 19 & 44.6 & 12.4 & 0.45 \\
\hline Females & 46 & 44.1 & 13.1 & & 36 & 44.4 & 12.8 & & 10 & 40.5 & 14.8 & \\
\hline \multicolumn{13}{|c|}{ Hispanics } \\
\hline Males & 40 & 40.2 & 15.0 & 0.08 & 15 & 39.0 & 19.6 & 0.07 & 25 & 39.9 & 14.1 & 0.34 \\
\hline Females & 30 & 46.1 & 15.2 & & 10 & 50.5 & 11.4 & & 20 & 44.4 & 16.8 & \\
\hline
\end{tabular}

Note: $* P$ is significant at levels $<0.05$.

Abbreviation: SD, standard deviation.

$16 \%$, OR $4.1,95 \%$ CI: $2.5-7.0, P=001)$ or fistulizing disease (65\% versus $19 \%$, OR $3.4,95 \%$ CI: $2.1-5.5$, $P=0.001)$. The fistulizing phenotype was seen twice as often in Hispanics than Caucasians or African-Americans, although this did not reach statistical significance, possibly due to the small sample size ( $32 \%$ versus $17 \%$, OR $2.0,95 \%$ CI: $0.7-5.5, P=0.20$, versus $16 \%$, OR $2.2,95 \%$ CI: $0.7-5.2$, $P=0.18$, respectively) (Figure 2). The overall rate of fistulizing, stricturing, and inflammatory $\mathrm{CD}$ was similar across all age groups and between male and female patients.

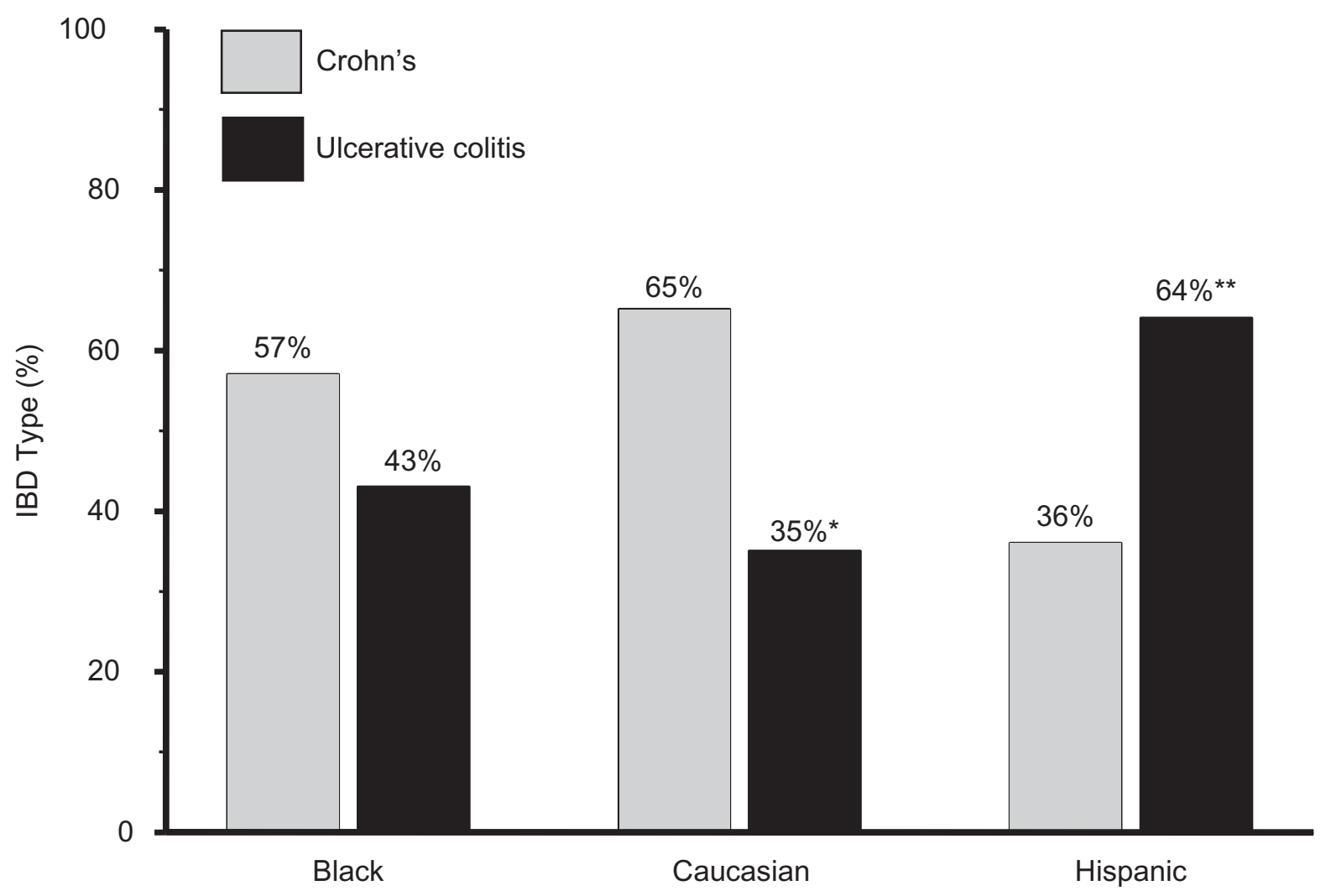

Ethnic Group

Figure I The CD:UC ratio among the total study population by race/ethnicity. Hispanics were diagnosed more often with UC than with CD, Caucasians were diagnosed more often with $C D$ than with $U C$, and African-Americans were diagnosed more often with $C D$ than with UC, but the difference was not significant.

Notes: $* P$ is significant at levels $<0.05$. $* * P$ is significant at levels $<0.00$ I.

Abbreviations: IBD; inflammatory bowel disease; CD, Crohn's disease; UC, ulcerative colitis. 


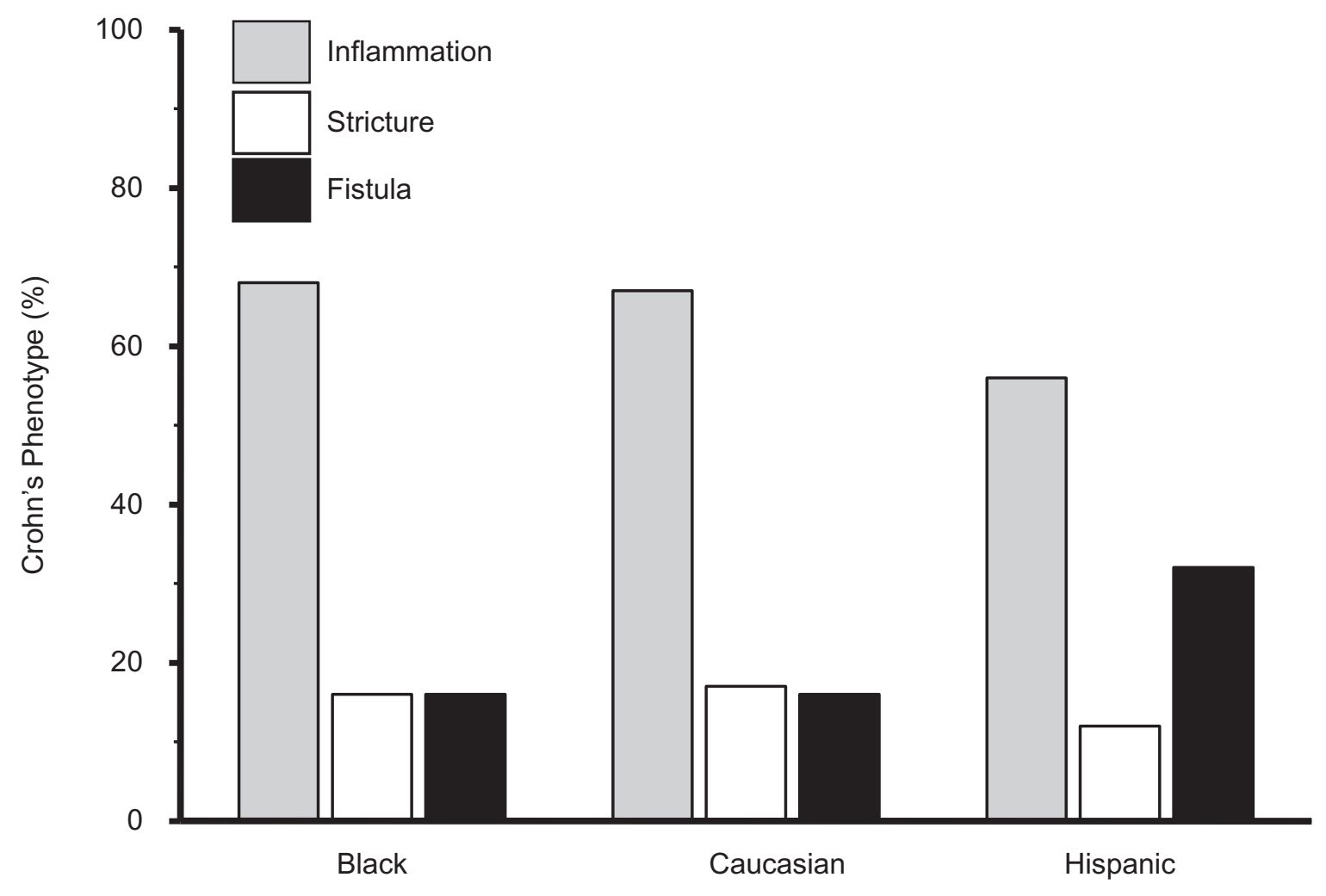

Ethnic Group

Figure 2 The distribution rates of Crohn's disease (CD) phenotype by race/ethnicity among the 147 patients with CD. Hispanics have twice the rate of fistualzing disease than African-Americans or Caucasians. There were no significant differences in the distribution rates of inflammation and strictures between the three ethnic groups.

\section{Ulcerative colitis characteristics}

The majority of the patients (62\%) with UC had pancolitis, $27 \%$ had left-sided colitis, and $11 \%$ had proctitis. This distribution was similar across all racial/ethnic groups. The mean age of patients with left-sided colitis was significantly higher than those with pancolitis or proctitis (age $50 \pm 14.1$ versus $41.5 \pm 14.4,41.2 \pm 13.4$, respectively; $P=0.05$ ). Females had a significantly higher rate of left colitis than males ( $30 \%$ versus $13 \%$, OR $2.1,95 \% \mathrm{CI}: 1.1-5.4, P=0.001)$. Males had a higher rate of pancolitis than females, but that difference was not significant ( $56 \%$ versus $42 \%$, OR $1.3,95 \%$ CI: $0.6-2.1, P=0.60$ ).

\section{Discussion}

Although IBD has been reported worldwide, most studies have focused on the Caucasian populations, and there is still a paucity of literature on the epidemiologic aspects of the disease in Hispanics and African-Americans. Moreover, IBD has not previously been studied in populations of low socioeconomic status. In this study of a multiethnic IBD population of predominantly low socioeconomic status, we found that Hispanics were diagnosed with $\mathrm{UC}$ more than $\mathrm{CD}$.
Our findings are consistent with the results reported from Puerto Rico that showed that a higher proportion of study patients were diagnosed with UC than with CD. ${ }^{13-15}$ This finding was also reported in another United States study in which Mexican-Americans predominantly had UC, compared with Caucasians and African-Americans, who predominantly had CD. ${ }^{16}$ An earlier study from a health maintenance organization database in California found that Hispanics had a lower prevalence of $\mathrm{CD}$ compared with both African-Americans and Caucasians. ${ }^{17}$ A systematic review of 28 publications encompassing 1272 Hispanic and 547 African-American patients with IBD found that a greater proportion of Hispanic patients were diagnosed with UC than with CD compared with African-American patients. ${ }^{18}$ On the contrary, Nguyen et al reported a higher frequency of CD compared with UC among a Puerto Rican population. ${ }^{11}$ This dissimilarity in the study results could be due to differences in the study design, the characteristics of the study population, or the differences in the genetic and environmental exposure(s) of the studied population.

The difference in the distribution rate of CD and UC across the three racial/ethnic groups emphasizes the potential role of 
genetics and environmental interaction on the etiology of IBD. A recent study reported that African-American and Hispanic CD patients, but not UC patients, had a lower prevalence of family history of IBD than their Caucasian counterparts, concluding that racial differences may reflect underlying genetic variations. ${ }^{11} \mathrm{It}$ is also worth pointing out that differences in diet and hygiene are changing over time and could play a role in the etiology of IBD. The high-fat intake diet among the African-American population could possibly contribute to the etiology of CD. A study from the United States among urban African-Americans found $77 \%$ of the study population had a diet that is very high in fat. ${ }^{19}$

The second novel finding of our study is the difference in the mean age of diagnosis between females and males. Female patients with IBD were diagnosed at a significantly older age than males. Although this trend was consistent among the three ethnic groups for UC, it was reversed among Caucasians diagnosed with $\mathrm{CD}$, as males were diagnosed later than females. This observation was not previously reported, and the clear reason for that difference is unknown. This finding could be due to true gender differences or because women had sought medical care for their symptoms later than men. It is less likely to be due to a high proportion of women treated in the studied hospital because, based on an HCHD internal source (unpublished data), 59\% of the patients treated between 2008 and 2009 were females. Nevertheless, IBD is a complex disease that is controlled by multiple risk factors, ${ }^{20}$ and the difference in age of diagnosis between genders deserves to be further studied.

Our results revealed similar rates of fistualizing disease in African-Americans and Caucasians with CD. This finding contradicts the concept that African-Americans diagnosed with $\mathrm{CD}$ have a more severe disease course than Caucasians ${ }^{21-22}$ but is in agreement with Deveaux et al, who reported that there was no difference in disease presentation between African-American and Caucasian patients who required surgery for $\mathrm{CD} .{ }^{23}$ Another study by Mahid et al has recently published a systemic review on the comparison of the course of IBD between African-Americans and Caucasians among over 2000 cases of IBD and reported similar findings to our results. ${ }^{12}$ Of interest, we found that the rate of fistulizing CD among Hispanics was double that of the other two ethnic groups. Because there are few published data on distribution and manifestation of IBD in Hispanics, we were not able to make a comparison with this finding in the literature. The Mid-Atlantic Crohn's Disease Study Group conducted a multicenter survey of African-American and Caucasian patients with $\mathrm{CD}$ who were matched by age, gender, and practice type (teaching versus private practice setting) and reported that African-American and Caucasian patients have similar disease course presentations. ${ }^{24}$

The utilization of data for constructing the current crosssectional study has some shortcomings. First, the retrospective nature of the data collection may be limited by incomplete documentation. However, the HCHD has a comprehensive system that details all radiology, endoscopy, pathology, and laboratory reports - data that are essential in the diagnosis and management of patients with IBD. The second limitation of the study is that we were not able to examine the effect of other races due to their small sample size. However, our study is the largest study comparing African-Americans, Hispanics, and Caucasians with IBD in the United States to date. In the 2000 Census, nearly $60 \%$ of the Hispanic population in the United States was of Mexican descent, which is similar to the majority of the Hispanic population of Harris County. Therefore, our data reflect the findings of a predominantly Mexican-American patient population with IBD. Our results could be more representative of the overall indigent Hispanic population in the United States. We also found that the three studied ethnic groups underwent similar rates of diagnostic testing during the study period. Finally, all patients within the HCHD have equal access to physicians, hospital facilities, and the pharmacy, thus eliminating potential provider or patient bias that may delay the diagnosis.

In conclusion, our study demonstrates clear evidence of the importance of the effect of ethnicity on the presentation and manifestation of IBD. Hispanics were diagnosed more frequently with UC, whereas African-Americans and Caucasians were diagnosed more frequently with $\mathrm{CD}$. Females were diagnosed with IBD at an older age than males, and the difference was consistent for the three racial/ethnic groups. Understanding the epidemiology of IBD requires better understanding of the interactions between environment, ethnic group, age, and socioeconomic conditions.

\section{Disclosure}

The authors report no conflicts of interest in this work.

\section{References}

1. Sandler RS, Everhart JE, Donowitz M, et al. The burden of selected digestive diseases in the United States. Gastroenterology. 2002;122: 1500-1511.

2. Baldassano RN, Piccoli DA. Inflammatory bowel disease in pediatric and adolescent patients. Gastroenterol Clin North Am. 1999;28: 445-458.

3. Marx G, Seidman EG, Martin SR, Deslandres C. Outcome of Crohn's disease diagnosed before two years of age. J Pediatr. 2002;140: 470-473.

4. Loftus EV Jr. Clinical epidemiology of inflammatory bowel disease: incidence, prevalence, and environmental influences. Gastroenterology. 2004;126:1504-1517. 
5. Weersma RK, Stokkers PC, Cleynen I, et al. Confirmation of multiple Crohn's disease susceptibility loci in a large Dutch-Belgian cohort. Am J Gastroenterol. 2009;104:630-638.

6. Su C, Lichtenstein GR. Recent developments in inflammatory bowel disease. Med Clin North Am. 2002;86:1497-1523.

7. Loftus EV Jr, Silverstein MD, Sandborn WJ, Tremaine WJ, Harmsen WS, Zinsmeister AR. Ulcerative colitis in Olmsted County, Minnesota, 1940-1993: incidence, prevalence, and survival. Gut. 2000; 46:336-343.

8. Loftus EV Jr, Silverstein MD, Sandborn WJ, Tremaine WJ, Harmsen WS, Zinsmeister AR. Crohn's disease in Olmsted County, Minnesota, 1940-1993: incidence, prevalence, and survival. Gastroenterology. 1998;114:1161-1168.

9. Vind I, Riis L, Jess T, et al; for the DCCD study group. Increasing incidences of inflammatory bowel disease and decreasing surgery rates in Copenhagen City and County, 2003-2005: a population-based study from the Danish Crohn colitis database. Am J Gastroenterol. 2006;101:1274-1282.

10. Finlay DG, Basu D, Sellin JH. Effect of race and ethnicity on perceptions of inflammatory bowel disease. Inflamm Bowel Dis. 2006;12: 503-507.

11. Nguyen GC, Torres EA, Regueiro M, et al. Inflammatory bowel disease characteristics among African Americans, Hispanics, and nonHispanic Whites: characterization of a large North American cohort. Am J Gastroenterol. 2006;101:1012-1023.

12. Mahid SS, Mulhall AM, Gholson RD, Eichenberger MR, Galandiuk S. Inflammatory bowel disease and African Americans: a systematic review. Inflamm Bowel Dis. 2008;14:960-967.

13. Moreno JM, Rubio CE, Torres EA. Inflammatory disease of the gastrointestinal tract at the University Hospital, Medical Center, Puerto Rico. 1980-1987 [in Spanish]. Bol Asoc Med P R. 1989;81:214-218.
14. Torres EA, de Jesús R, Pérez CM, et al. Prevalence of inflammatory bowel disease in an insured population in Puerto Rico during 1996. P R Health Sci J. 2003;22:253-258.

15. Appleyard CB, Hernández G, Rios-Bedoya CF. Basic epidemiology of inflammatory bowel disease in Puerto Rico. Inflamm Bowel Dis. 2004; 10:106-111.

16. Basu D, Lopez I, Kulkarni A, et al. Impact of race and ethnicity on inflammatory bowel disease. Am J Gastroenterol. 2005;100:2254-2261.

17. Kurata JH, Kantor-Fish S, Frankl H, Godby P, Vadheim CM. Crohn's disease among ethnic groups in a large health maintenance organization. Gastroenterology. 1992;102:1940-1948.

18. Hou JK, El-Serag H, Thirumurthi S. Distribution and manifestations of inflammatory bowel disease in Asians, Hispanics, and African Americans: a systematic review. Am J Gastroenterol. 2009;104:2100-2109.

19. di Noia J, Schinke SP, Contento IR. Dietary fat intake among urban, African American adolescents. Eat Behav. 2008;9:251-256.

20. Kugathasan S, Amre D. Inflammatory bowel disease - environmental modification and genetic determinants. Pediatr Clin North Am. 2006;53: 727-749.

21. Sonnenberg A, McCarty DJ, Jacobsen SJ. Geographic variation of inflammatory bowel disease within the United States. Gastroenterology. 1991;100:143-149.

22. Agrez MV, Valente RM, Pierce W, Melton LJ 3rd, van Heerden JA, Beart RW Jr. Surgical history of Crohn's disease in a well-defined population. Mayo Clin Proc. 1982;57:747-752.

23. Deveaux PG, Kimberling J, Galandiuk S. Crohn's disease: presentation and severity compared between black patients and white patients. Dis Colon Rectum. 2005;48:1404-1409.

24. Straus WL, Eisen GM, Sandler RS, Murray SC, Sessions JT; Crohn's disease: does race matter? The Mid-Atlantic Crohn's Disease Study Group. Am J Gastroenterol. 2000;95:479-483.
Clinical and Experimental Gastroenterology

\section{Publish your work in this journal}

Clinical and Experimental Gastroenterology is an international, peerreviewed, open access journal, publishing all aspects of gastroenterology in the clinic and laboratory, including: Pathology, pathophysiology of gastrointestinal disease; Investigation and treatment of gastointestinal disease; Pharmacology of drugs used in the alimentary tract;

\section{Dovepress}

Immunology/genetics/genomics related to gastrointestinal disease. This journal is indexed on CAS. The manuscript management system is completely online and includes a very quick and fair peer-review system. Visit http://www.dovepress.com/testimonials.php to read real quotes from published authors. 